\title{
A PERSPECTIVA INTERACIONISTA DO ENSINO DE LÍNGUA PORTUGUESA: CONTRIBUIÇÕES A EDUCAÇÃO AMBIENTAL
}

\author{
Joelma Madruga Furtado ${ }^{1}$ \\ Darlene Silveira Cabrera ${ }^{2}$ \\ Denise Bastos das Neves ${ }^{3}$ \\ Luis Fernando Minasi ${ }^{4}$
}

Resumo: $O$ presente trabalho emerge da discussão acerca da temática da proposta do ensino de Língua Portuguesa embasada na concepção interacionista orientada pelos PCNs, os quais indicam o trabalho a partir dos Gêneros Textuais, documento que também traz à discussão a necessidade do desenvolvimento dos Temas Transversais por meio de todas as disciplinas, entre eles a Educação Ambiental. Temática essa que deve permear a formação de professores de Língua Portuguesa, tendo em vista a necessidade de discutila, possibilitando, assim, a sua inferência em todas as Etapas e Modalidades de ensino, oportunizando aos professores envolvidos sentirem-se pertencentes a esses espaços, como também comprometidos tanto com sua formação inicial quanto com a formação continuada, no que diz respeito ao trabalho com a linguagem numa perspectiva sociointeracionista. Concepção esta que considera a linguagem como produto da interação social, tratando de reintroduzir nos estudos da linguagem o aspecto social, interacional, comprometida com uma educação linguística que transforme para melhor a vida das pessoas.

Palavras-chave: Ensino de Língua Portuguesa; Perspectiva Sociointeracionista; Educação Ambiental.

1 Universidade Federal do Rio Grande. E-mail: adodavi@gmail.com

2 Universidade Federal do Rio Grande. E-mail: darlenescabrera@gmail.com

3 Universidade Federal do Rio Grande. E-mail: denisentx@hotmail.com

4 Universidade Federal do Rio Grande. E-mail: Ifminasi@terra.com.br

Revbea, São Paulo, V. 13, № 4: 369-378, 2018.

revista brasileira educação ambiental 


\section{Introdução}

Por meio de um breve resgate histórico, abordamos como se instituiu o ensino tradicional (ou normativo) de língua, no Brasil. Lembra-nos Marcuschi (2001) que, no Brasil-Colônia, o ensino de língua voltava-se apenas para a alfabetização. Reportamo-nos aos aspectos teóricos para situar o estudo da Língua Portuguesa então instituído pela Reforma Pombalina, em 1759. Época e teoria que consideram como modelo de língua os escritores clássicos seguindo os aspectos da gramática, retórica e poética como também os preceitos da Filologia. A ideia de que a língua formava um grande quadro da identidade nacional e era a depositária da cultura nacional dá origem à visão de língua da Lei no 5.692/71 como "expressão da cultura brasileira". A língua estaria dispensada a ser o patrimônio e a pátria de um povo. Assim como, sob o ponto de vista jurídico, a língua é vista como constituinte da identidade nacional. Esse parecer emerge da visão oficial conservadora da língua - ao eleger a variedade linguística usada pelos grupos de poder como o código aceito "oficialmente" e, portanto, representante da identidade nacional.

Entretanto, é importante considerar que, por um lado, a variedade linguística não interfere na constituição da unidade nacional, posto que a natureza da língua é intrinsecamente heterogênea, e, por outro, também não vemos retratados o "patrimônio e a pátria" do povo brasileiro em outros países que falam a língua portuguesa, como em alguns países da África e mesmo em Portugal. Consideramos essencial salientar que a língua é parte integrante da identidade nacional, no entanto não é determinante, o que relativiza a imagem da língua como formadora da identidade nacional.

A concepção de língua como expressão do pensamento, que predominou exclusivamente na produção de manuais normativos para o ensino de língua até o final do século XIX, permanece ainda hoje nas concepções mais conservadoras, ao não admitirem outro ensino a não ser o da língua padrão, verificada nos cânones literários. Logo, é dessa concepção que decorre a noção de erro, associada aos preceitos da gramática normativa, como tudo aquilo que foge à variedade eleita como modelo de correção da linguagem, fomentando o mito de que as pessoas que não conseguem se expressar segundo a modalidade padrão não sabem também pensar.

A chamada variedade culta ou padrão associa-se a um padrão cultural fixado na tradição escrita - por estar ao alcance de uma parcela restrita da comunidade, o que Ihe dá um status diferenciado, transformando-a no veículo utilizado na transmissão de informações políticas e culturais. Como Bagno nos leva a refletir sobre se seria uma ameaça à sociedade em que vivemos trazer à tona a democratização do saber linguístico, a divulgação ampla das descobertas deste campo científico, a liberação da voz de tantos milhões de pessoas condenadas ao silêncio por "não saber português ou por falar tudo errado?" (BAGNO, 2006, p.165).

Em consonância com a concepção de linguagem como expressão do pensamento, a Lei 5.692/71, atua no sentido de fixar a norma culta da língua 
como expressão da cultura brasileira. No entanto, esse ideal baseia-se em uma concepção estática e homogênea de língua, pois pensa na sua unidade, sem considerar que a língua varia e que, portanto, conhecer uma língua é conhecer as suas variedades para o manejo social (FIORIN, 2001). Além da concepção de linguagem como expressão do pensamento, não podemos deixar de dar evidência a outra concepção ressaltada pela LDB em questão, em decorrência da ênfase ao tecnicismo: a linguagem como instrumento de comunicação.

Enquanto a primeira caracteriza a visão tradicional de gramática como um conjunto de regras a serem seguidas, a segunda está presente no estruturalismo, que concebe a gramática como uma relação de estruturas, passível de classificação e descrição científica. Diferentemente do normativismo, o estruturalismo propõe descrever a língua tal como é falada por determinada comunidade, em determinada época.

No entanto, a operacionalização dessa concepção acaba por limitar-se à descrição da norma culta, uma vez que ao estruturalismo interessa a abstração linguística e não propriamente a realização linguística concreta de cada falante.

Ao ver a língua como instrumento de comunicação, do qual o falante se apropria para transmitir uma mensagem, essa concepção, como nos afirma Travaglia (2001) fez com que a Linguística não considerasse os interlocutores e a situação de uso como determinantes das unidades e regras que constituem a língua, isto é, afastou o indivíduo falante do processo de produção, do que é social e histórico na língua. Assim, desvalorizou estudos voltados a aspectos semânticos pragmáticos, sociais, discursivos e cognitivos, destacando a língua como objeto autônomo que, como salienta Marcuschi (2001), age por si só, independentemente da posição do sujeito falante.

Apesar de não dar conta, como declarou Noam Chomsky (1972) do uso criativo da língua, o estruturalismo acarretou grande avanço no estudo dos aspectos formais da língua e o abandono do método dedutivo adotado pela gramática tradicional (apresentação das formas > regras de emprego > exemplos > exercícios-testes) em função do método indutivo (exemplos > exercícios estruturais > testes eventuais), que permitiria aos alunos automatizar exemplos para a prática da língua falada.

Ao chegar ao Brasil, na década de 1970, o modelo estruturalista da língua coincidiu com o momento histórico vivido pelo país, pautado no tecnicismo, sendo assim esse foi o priorizado pela LDB nำ5.692/71 e passou a dominar, desde então, o cenário do ensino de língua. Desta forma, a língua nacional ensinada na escola adquiriu um caráter emblemático, servindo de instrumento de dominação ao poder político e militar, porque a própria concepção de língua corrente isentou as instituições de propiciar a reflexão e o posicionamento do sujeito, em face de um ensino centrado na repetição mecânica da estrutura da língua. A língua como representante do meio.

Compreendemos que a vida em grupo estabeleceu diferentes formas de comunicação. Logo, os homens em formação chegariam a um ponto em comum: eles teriam algo para dizer. Corroborando essa reflexão, de como 
nasceu a linguagem, Cheptulin (1982) afirma que com a linguagem a consciência recebeu uma forma material de existência correspondente a sua natureza social.

Nesse sentido, consideramos a partir de Marx e Engels que a "linguagem é tão antiga quanto à consciência; a linguagem é a consciência real, prática” (MARX; ENGELS, 2007, p.44) que existe simultaneamente tanto para mim quanto para os outros. Isto é, a linguagem representa a consciência que os seres humanos têm do mundo, suas interpretações e concepções sobre o real. Vygotsky (2008, p. 09), nesse mesmo viés, diz que "o homem, por assim dizer é moldado pelos instrumentos e ferramentas que usa, e nem a mente nem a mão podem, isoladamente, realizar muito". Desta forma, os instrumentos e seus produtos são os fluxos da linguagem interiorizada e do pensamento conceitual, que algumas vezes caminham paralelamente e outras se fundem, um influenciando o outro. Para sustentar esta ideia, salientamos que a linguagem é uma atividade mediada, necessária para a compreensão dos processos cognitivos. Os conceitos e a linguagem que os infundem dão força e estratégia à atividade cognitiva, e nessa linha entendemos o papel da Língua Portuguesa como expressão da representação social dessas mediações. Além disso, Bakhtin (1999) salienta que a cada época histórica da vida ideológica e verbal, de acordo com sua geração e em cada uma de suas camadas sociais, possui sua linguagem; não obstante, cada grupo etário tem seu "falar", seu vocabulário, seu sistema prosódico que, por sua vez, variam segundo a classe social, a instituição escolar e outros fatores de estratificação. No entanto, em forma mais ou menos direta, os valores e as concepções de mundo dos grupos locutores, determinados social e historicamente, determinam a sua língua.

No que diz respeito à palavra, essa não se reporta a um objeto isolado. Acerca desse aspecto, vale salientar que a dominação de classe dá-se e consolida-se por meio da dominação de linguagem. "Em uma sociedade dada, a linguagem dominante tende a ser a linguagem da classe dominante. $A$ hegemonia de uma classe impõe-se igualmente pela hegemonia de sua linguagem" (CARBONE; MAESTRI, 2003, p.105).

Portanto, cabe uma crítica, aqui, tanto no país quanto na própria escola continua-se discriminando sob forma sistemática variantes fonéticas não padrão próprias das classes subalternizadas. Permanece o autoritarismo linguístico o qual é permitido e exercido sobretudo devido à posição social e funcional dominante, seja na escola, na universidade, na editoria, nos meios de comunicação, etc.

A verdadeira comunicação humana avança ao significado da palavra. $\mathrm{Na}$ concepção de Vygotsky (1984), as formas mais elevadas da comunicação humana somente são possíveis porque o pensamento do homem reflete uma realidade e a conceitua (conceitualizada). Desse modo, o verdadeiro curso do desenvolvimento do pensamento não vai do individual para o socializado, mas do social para o individual. Desse modo, ao compreendermos que a linguagem se organiza do coletivo para o individual como reflexo de determinado contexto social, concebemos, igualmente, que é a partir dela - de sua forma interacional Revbea, São Paulo, V. 13, № 4: 369-378, 2018. 
entre os seres humanos - que podemos propor e organizar outro ambiente social. Ambiente esse, o qual estamos entendendo enquanto meio natural ou enquanto meio construído pelo homem, no qual se dão as relações sociais.

Isso significa dizer que dependendo das interações que estabelecemos com a natureza natural e com os outros seres humanos em sociedade, teremos constituído determinado arcabouço essencial da linguagem. Isso equivale a dizer que meio natural ou o meio construído pelos seres humanos é o lugar em que essas interações acontecem - assim dependendo da constituição desse lugar e suas variantes podem surgir as diferentes constituições de língua.

Nesse sentido, consideramos que a Língua Portuguesa não deixa de ser a nossa língua, porém cada pessoa, em seu meio/região adapta-se à sua maneira de comunicação. Cada pessoa tem suas características e seus vícios de linguagem derivados de sua própria história. Cada palavra, cada expressão remete a um ou a diversos contextos nos quais ela vivenciou sua existência socialmente subentendida. No entanto, entendemos que é por meio das interações que a linguagem cria corporeidade, acontecendo prioritariamente sob duas formas: interação mundo-pessoa e interação pessoa-pessoa, equivalente a interação. Linguisticamente, entre as pessoas são chamadas de "comunicação" e as interações mundo-pessoa, consideradas como "referência", nomeação, denotação, representação ou significação.

Sobretudo, "[...] todas as palavras, todas as formas estão povoadas de intensões" (BAKHTIN, 1999 p.161). Todavia, a palavra do outro procura definir as bases mesmas de nosso comportamento e de nossa atitude em relação ao mundo.

A sociedade determina formas sutis de linguagem - por meio de uma proposta de uma linguagem neutra, própria a toda a comunidade, viabilizando a imposição permanente de conteúdos das classes dominantes aos seguimentos dominados, sobre seus interesses. A palavra nunca é neutra, ela é uma construção social e histórica com vínculos essenciais com a formação social de seus locutores.

Com base nessa discussão é importante apontarmos que toda reflexão sobre a Língua Portuguesa, seja sobre seu ensino ou pesquisa em quaisquer de seus aspectos, conduz ao pleno domínio das habilidades linguísticas. A linguagem como atividade cognitiva e discursiva e o domínio da língua, como sistema simbólico utilizado por uma comunidade linguística são instrumentos indispensáveis de participação dos seres humanos em sociedade.

\section{Ensino da Língua Portuguesa sob o enfoque interacionista contribuição à Educação Ambiental}

Compreendemos que o ensino de Língua Portuguesa tem a especial responsabilidade de traduzir um trabalho imbuído de uma concepção interacionista sobre a linguagem. De tal forma, estamos considerando essa abordagem interacionista da linguagem enquanto contribuição ao Campo da

revista brasileira educação ambiental 
Educação Ambiental, devido seu objetivo principal de socialização do ser humano, ao passo que esse conhece a si próprio, conhece, também, o meio no qual está imerso. Assim, concebemos, a partir de Marcuschi (2008), que a linguagem que deve sustentar o currículo de Língua Portuguesa é aquela em que a sala de aula constitui um grande laboratório de investigação, onde conhecer não é um ato individual, mas uma ação cooperativa. Dessa forma, corroborando com a perspectiva crítica da Educação Ambiental, e, simultaneamente, superando a pedagogia em que o professor se limita a transmitir ou repetir o já sabido (FREIRE, 2015), a linguagem passa a proporcionar condições para garantir a construção coletiva do conhecimento.

Aliamos nosso entendimento sobre os estudos da linguagem e sua contribuição à Educação Ambiental aos postulados por Bakhtin (1997), ao concebermos a linguagem como processo de interação, logo, a língua aparece em contextos de enunciação definidos, remetendo, sempre, a contextos ideológicos, o que corrobora com o posicionamento de que nenhuma palavra é neutra, mas sempre carregada de sentido, tanto pelo locutor quanto pelo interlocutor, caracterizando-se enquanto ponte. Para este autor, a palavra está sempre carregada de um conteúdo ou de um sentido ideológico ou vivencial. "[...] A língua, no seu uso prático, é inseparável de seu conteúdo ideológico ou relativo à vida" (BAKHTIN, p.47, 1997).

Consideramos que $o$ ato de fala ou, ainda, a enunciação em si, não pode ser considerada como individual, unicamente do ponto de vista da norma, mas ao contrário, a enunciação é de natureza social, de relação dialógica e seu elemento principal é a interação verbal. Bem como, entendemos a partir de Geraldi (1997), que a linguagem não é o trabalho de um artesão, mas trabalho social e histórico dos sujeitos, sendo que é para os outros e com os outros que ela se constitui.

Posto que a linguagem seja vista como processo de interação, a língua é usada não apenas para a comunicação, também, para estabelecer a interação social. O indivíduo realiza ações, atua sobre o interlocutor, afirmação que está de acordo com Travaglia (2001) ao nos dizer que a linguagem é, pois, um lugar de interação humana, de interação comunicativa pela produção de efeitos de sentidos entre interlocutores, em uma dada situação de comunicação e em um contexto sócio histórico e ideológico. Logo, a língua não deixa de ser expressão e comunicação, mas, além disso, passa a ser uma atividade socio interativa.

É importante salientarmos que trabalhar a Língua Portuguesa, a partir da concepção de Marcuschi, resulta em oportunizar, na sala de aula, um conjunto integrado de atividades de leitura e de produção de textos orais e escritos. Assim, destacamos como fundamental entender a necessidade do estudo da linguagem embasado na concepção interacionista, a qual contribui ao Campo da Educação Ambiental Revolucionária, questionadora dos paradigmas ideológicos estabelecidos pelo capital, enquanto ação, ao ser analisada como atividade e não apenas pela decodificação do código linguístico. 
Em consonância com essas posições e suporte teórico, sugerimos mostrar que todo uso e funcionamento significativo da linguagem ocorrem em textos e discursos produzidos e recebidos em situações enunciativas ligadas a domínios discursivos da vida cotidiana e realizados em gêneros que circulam na sociedade. Os pressupostos teóricos- metodológicos trazidos pelos PCNs, direcionam ao desenvolvimento de projetos pedagógicos que contemplam os Temas Transversais, sendo assim consideramos as aulas de Língua Portuguesa um espaço sólido - dentro das disciplinas que pertencem ao Núcleo Comum do currículo - para o desenvolvimento de potencialidades para a formação de leitores/escritores críticos e atuantes de acordo com os princípios suliadores ${ }^{5}$ da Educação Ambiental.

Uma vez que as práticas de linguagem são uma totalidade e que o sujeito expande sua capacidade de uso da linguagem e de reflexão sobre ela em situações significativas de interlocução, entendemos que as propostas pedagógicas de ensino de Língua Portuguesa devem organizar-se tomando o texto (oral ou escrito) como unidade básica de trabalho considerando a diversidade de textos que circulam socialmente. Destarte, propõe-se que as atividades planejadas sejam organizadas de maneira a tornar possível a análise crítica dos discursos para que o estudante possa identificar pontos de vista, valores e eventuais preconceitos neles veiculados.

Assim organizado, concebemos que o ensino de Língua Portuguesa sob um enfoque interacionista, contribuindo ao desenvolvimento da postura crítica que propõe a Educação Ambiental, possibilita constituir-se em fonte legítima de autonomia para o sujeito, condição para a participação social responsável. Sendo o domínio da língua, oral e escrita, fundamental para a participação social efetiva, pois é por meio dela que o homem se comunica, tem acesso à informação, expressa e defende pontos de vista, partilha ou constrói concepções de mundo, produz conhecimento. Por isso, ao ensiná-la, a escola tem a responsabilidade de garantir a todos os seus estudantes o acesso aos saberes linguísticos necessários para o exercício da cidadania - direito inalienável de todos.

\section{Nossas considerações}

As discussões aqui apresentadas nos suscitam outros questionamentos a respeito das possibilidades que surgem a partir da proposta do trabalho com a linguagem estar embasado na concepção interacionista, a qual vem discutir a importância da relação dialógica entre os sujeitos, explicitando a compreensão crítica dos textos, bem como a função da Língua Portuguesa

\footnotetext{
${ }^{5}$ Suliar, termo usado por Paulo Freire para contrapor o significado de Nortear. Alertado pelo físico Márcio Campos, atualmente dedicado à etnocência, à etnoastronomia e à educação ambiental - sobre ideologia implícita do vocabulário nortear, marcando as diferenças de níveis de "civilização" e de "cultura", bem a gosto positivista, entre o hemisfério Norte e o Sul, entre "criador" e o "imitador".
}

revista brasileira educação ambiental 
dentro das disciplinas do Núcleo Comum do currículo, onde se propõe pensar e repensar a Educação Ambiental como prática pedagógica por meio dos Temas Transversais, conforme orienta o PCNs.

Com um embasamento que se contrapõe ao Normativismo, o ensino de língua deve possibilitar a leitura do contexto, não sendo apenas uma memorização mecânica de palavras, mas numa relação dinâmica que vincula linguagem e realidade - proposta central do Interacionismo.

$\mathrm{Na}$ evolução histórica da humanidade, o que vimos a respeito do ensino da Língua Portuguesa foi a imposição do ensino de uma língua dita como padrão - a língua culta, língua essa determinada pela classe dominante. Em nossa concepção, é indispensável que a proposta socio interacional oportunize um processo que contemple uma compreensão crítica daquilo que se lê, onde se emancipa os sentidos para além da decodificação pura da linguagem escrita, contudo que se compreenda que linguagem e realidade estão imbricadas, numa relação de dialogicidade, cabendo entender como acontecem as relações entre texto e contexto.

Sendo assim, segundo Antunes (2007), no âmbito dos estudos sobre a linguagem, passam a ter prioridades conteúdos, objetivos e práticas pedagógicas que privilegiem a dimensão ampla e funcional da linguagem - 0 que certamente incidirá sobre transformações na escola se tais dimensões forem realmente o centro do ensino e aprendizagem de línguas.

Trazendo às discussões essa concepção, tudo o que está a serviço da língua vem como proposta a desencadear outra forma de trabalho, logo, é importante enfatizar que a leitura dos mais variados textos nos também mais variados suportes textuais não significam uma ruptura do o trabalho com a linguagem, pelo contrário, o texto está impregnado de sentido - e é este espaço que a Educação Ambiental tem de galgar dentro da Língua Portuguesa. Como Tema Transversal trazer a inquietação necessária para que se fomente o debate acerca dessa temática.

Nesse processo, tudo o que está a serviço da língua vem como proposta a aguçar a criticidade, de forma dinâmica, viva, no movimento dos textos, não como vocábulos estáticos, mas que necessitam ser desvelados dentro do contexto ao qual pertencem. E é na base dessa cisão que a Educação Ambiental compõe esse movimento dinâmico, em que necessitamos compreender qual e como se expressa o campo da Educação Ambiental, como também quais inquietações carregam de significação esse campo.

$\mathrm{Na}$ medida em que compreendermos qual educação temos e qual educação almejamos, estaremos nos posicionado de forma crítica, superando a concepção da leitura apenas da palavra, mas propondo-nos a uma leitura mais rigorosa de mundo. 


\section{Referências}

ANTUNES, I. Muito além da gramática: por um ensino sem pedras no caminho. São Paulo: Parábola Editorial, 2007.

BAGNO, M. Preconceito linguístico: o que é, como se faz. 43 ed. São Paulo: Edições Loyola, 2006.

BAKHTIN, M. Gêneros do discurso. In: Estética da criação verbal. PEREIRA, M. E. G. G. São Paulo: Martins Fontes, 1992.

BAKHTIN, M. Problemas da poética de Dostoievski. 2. ed. Trad. Paulo Bezerra. Rio de Janeiro: Forense Universitária, 1997.

BAKHTIN, M. Esthétique et héorie du romam. Paris: Gallimard, 1999.

BRASIL. Parâmetros Curriculares Nacionais: introdução aos parâmetros curriculares nacionais. Secretaria de Educação Fundamental. - Brasília: MEC/SEF, 1997.

BRASIL. Secretaria de Educação Fundamental. Parâmetros curriculares nacionais: terceiro e quarto ciclos do Ensino Fundamental/Língua Portuguesa, Brasília: MEC/SEF, 1998.

BRASIL. Secretaria de Educação Básica. Diretrizes Curriculares Nacionais Gerais da Educação Básica. Ministério da Educação. Brasília, 2013.

CARBONI, F. A linguagem escravizada: língua, histórica, poder e luta de classes. Florence Carboni, Mário Maestri. - São Paulo: Expressão Popular, 2013.

CHEPTULIN, A. A dialética materialista: categorias e leis da dialética. Trad. Leda Rita Cintra Ferraz. São Paulo: Alfa-Omega, 1982.

CHOMSKY, N. Linguística Cartesiana: um capítulo da história do pensamento racionalista. Trad. Francisco M. Guimarães. São Paulo: EdUSP, 1972.

FARACO, C.A. A Linguística histórica: uma introdução ao estudo da história das línguas. São Paulo: Parábola Editorial, 2005.

FIORIN, J.L. Considerações em torno do projeto de Lei no1676/99. In: FARACO, C. A. (org.) Estrangeirismos - Guerras em torno de uma língua. $2^{\mathrm{a}}$ ed. São Paulo: Parábola, 2001.

FREIRE, P. Pedagogia da Autonomia - Saberes necessários à prática educativa. São Paulo: Paz e Terra, 1996.

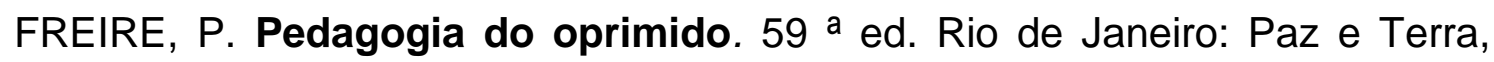
2015.

GERALDI, J.V. O texto na sala de aula - Leitura \& Produção. $2^{\underline{a}}$ ed. Cascavel: ASSOESTE, 1985.

GERALDI, J.V. Concepções de linguagem e o ensino de Português. In: O texto na sala de aula. São Paulo. Ática, 1997. 
MARCUSCHI, L. A. (org.) Formação do educador - avaliação \& currículo. Recife: Editora UFPE, 2001.

MARCUSCHI, L. A. Produção textual, análise de gêneros e compreensão. São Paulo: Parábola Editorial, 2008.

MARX, K; ENGELS, F. A Ideologia Alemã. São Paulo: Editora Moraes, 2009.

SAVIANI, D. Educação: do senso comum à consciência filosófica. São Paulo: Cortez Editora, 1982.

SAVIANI, D. Da nova LDB ao novo Plano Nacional de Educação: por outra política educacional. Campinas: Autores Associados, 1998.

TRAVAGLIA, L. C. Gramática e interação: uma proposta para o ensino de

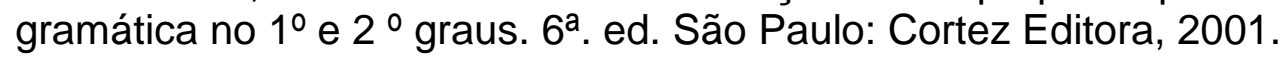

VYGOTSKY, L.S. A formação social da mente. São Paulo: Martins Fontes, 1984.

VYGOTSKY, L.S. Pensamento e Linguagem. 4a ed., São Paulo: Martins Fontes, 2008. 